\title{
PENDEKATAN BAYESIAN LINEX PADA MODEL SURVIVAL EKSPONENSIAL - GAMMA UNTUK MENENTUKAN PREMI DWIGUNA $k$ - TAHUN
}

\author{
Fitriani Hartati, Setyo Wira Rizki, Naomi Nessyana Debataraja
}

\begin{abstract}
INTISARI
Asuransi merupakan transaksi pertanggungan yang melibatkan dua pihak, tertanggung dan penanggung. Tertanggung diwajibkan membayar sejumlah uang kepada si penanggung, yang biasa disebut sebagai premi. Tujuan penelitian ini menentukan premi dwiguna $k$-tahun menggunakan pendekatan Bayesian Linex. Distribusi prior yang digunakan adalah distribusi gamma. Distribusi prior dan fungsi likelihood digunakan untuk menentukan distribusi posterior yang menjadi dasar untuk memperoleh estimasi Bayesian. Bayesian Linex merupakan satu dari fungsi kerugian (loss function) yang digunakan dalam menentukan metode survival. Metode survival diaplikasikan untuk memperoleh nilai premi dwiguna $k$-tahun. Data yang digunakan yaitu data usia seseorang dari 1 sampai 50 tahun dengan jangka 10 tahun, 15 tahun, dan 20 tahun. Diperoleh harga premi tunggal bersih dwiguna pada seseorang yang berusia 1 sampai 50 tahun dengan manfaat yang akan diperoleh Rp100.000.000 dengan jangka 10 tahun sebesar Rp58.421.345, jangka 15 tahun sebesar Rp55.871.644, dan berjangka 20 tahun sebesar Rp47.732.427. Berdasarkan nilai tersebut, semakin lama jangka waktu pembayaran maka harga premi semakin murah.
\end{abstract}

Kata Kunci: Bayesian Linex, Asuransi, Premi Dwiguna

\section{PENDAHULUAN}

Asuransi atau pertanggungan adalah perjanjian antara dua pihak atau lebih, dimana pihak penanggung mengikatkan diri kepada tertanggung, dengan menerima premi asuransi. Pihak penanggung memberikan penggantian kepada tertanggung karena kerugian, kerusakan atau kehilangan keuntungan yang diharapkan tertanggung, atau tanggung jawab hukum kepada pihak ketiga yang mungkin akan diderita tertanggung [1]. Asuransi jiwa merupakan transaksi pertanggungan yang melibatkan dua pihak, tertanggung dan penanggung. Penanggung menjamin pihak tertanggung, bahwa ia akan mendapatkan penggantian terhadap suatu kerugian yang mungkin akan dideritanya, sebagai akibat dari suatu peristiwa yang semula belum tentu akan terjadi atau yang semula belum dapat ditentukan saat atau kapan terjadinya. Tertanggung diwajibkan membayar sejumlah uang kepada si penanggung, yang biasa disebut sebagai premi. Premi bisa dibayarkan saat diawal kontrak atau dicicil dalam jangka waktu tertentu. Perhitungan premi asuransi jiwa ada beberapa hal yang harus dipertimbangkan yaitu mortalita, bunga dan biaya. Faktor bunga dan biaya umumnya sama untuk semua pemegang polis, tetapi faktor mortalita bergantung pada karakteristik pribadi tertanggung.

Asuransi jiwa terdiri dari asuransi jiwa seumur hidup, asuransi jiwa berjangka, dan asuransi jiwa dwiguna (endowment). Jenis asuransi jiwa dwiguna merupakan kombinasi antara asuransi jiwa berjangka dengan dwiguna murni (pure endowment). Polis ini menjanjikan pembayaran manfaat kepada ahli waris tertanggung, bila tertanggung mengalami kematian dalam jangka waktu mengikuti polis atau pembayaran manfaat kepada tertanggung bila ia hidup sampai akhir masa kontrak asuransi. Berdasarkan hal tersebut, asuransi dwiguna memiliki dua elemen yaitu perlindungan jiwa dan tabungan sehingga tertanggung dan ahli waris dapat memperoleh manfaat [2].

Penelitian ini bertujuan untuk menentukan premi dwiguna $k$-tahun menggunakan pendekatan metode Bayesian Linex. Estimasi parameter dilakukan menggunakan pendekatan Bayesian. Metode Bayesian memandang parameter sebagai variabel yang menggambarkan pengetahuan awal tentang 
parameter sebelum pengamatan dilakukan dan dinyatakan dalam suatu distribusi yang disebut dengan distribusi prior [3]. Informasi dalam distribusi prior dikombinasikan dengan informasi data sampel melalui teorema Bayes, dan hasilnya dinyatakan dalam bentuk distribusi posterior yang selanjutnya menjadi dasar untuk inferensi dalam metode Bayesian [4].

\section{DISTRIBUSI SURVIVAL}

Waktu survival $(T)$ merupakan variabel random non-negatif dari individu-individu dalam populasi yang merupakan variabel random kontinu dalam interval $[0, \infty)$ atau waktu survival pada waktu $t$ dengan $t \geq 0$ [5]. Distribusi waktu survival dapat dinyatakan dengan tiga fungsi yaitu, fungsi kepadatan peluang dan fungsi survival. Hal ini berarti jika salah satu dari persamaan fungsi diketahui, maka fungsi lainnya dapat ditentukan. Berikut ini fungsi dari distribusi survival sebagai berikut:

\section{Fungsi Kepadatan Peluang (probability density function)}

Fungsi kepadatan peluang atau yang disebut (pdf) probability density function adalah peluang suatu individu mati atau mengalami kejadian sesaat dalam interval waktu $t$ sampai $t+\Delta t$, dirumuskan sebagai berikut:

$$
f(t)=\lim _{\Delta t \rightarrow 0}\left[\frac{P(t<T<(t+\Delta t))}{\Delta t}\right]=\lim _{\Delta t \rightarrow 0}\left[\frac{F(t+\Delta t)-F(t)}{\Delta t}\right]
$$

Jika $T$ merupakan variabel acak non-negatif pada interval $[0, \infty)$ maka $F(t)$ merupakan fungsi distribusi kumulatif kontinu dari $T$. Sehingga dapat didefinisikan sebagai berikut:

$$
F(t)=P(T \leq t)=\int_{0}^{t} f(x) d x
$$

\section{Fungsi Survival}

Fungsi survival $S(t)$ didefinisikan sebagai peluang suatu individu dapat bertahan hidup dengan waktu survival sampai dengan waktu $t$ dengan $(t \geq 0)$ sebagai berikut:

$$
S(t)=1-P(T \leq t)=1-F(t)
$$

\section{DISTRIBUSI EKSPONENSIAL}

Jika $T$ adalah waktu tahan hidup yang mengikuti distribusi eksponensial dengan parameter $\theta$, fungsi kepadatan peluang distribusi eksponensial adalah

$$
f(t)= \begin{cases}\theta e^{-\theta t} & t \geq 0, \theta>0 \\ 0 & t<0\end{cases}
$$

Berikut ini adalah fungsi distribusi kumulatif untuk distribusi eksponensial:

$$
F(t ; \theta)=1-e^{-\theta t}
$$

\section{DISTRIBUSI GAMMA}

Distribusi gamma berasal dari fungsi gamma yang sudah dikenal luas dan juga dipelajari dalam banyak bidang matematika. Fungsi Gamma didefinisikan sebagai berikut :

$$
\Gamma(\alpha)=\int_{0}^{\infty} x^{\alpha-1} e^{-x} d x \quad \alpha>0
$$




\section{ANALISIS METODE BAYESIAN}

Pendekatan Bayesian memandang parameter $\theta$ sebagai variabel acak yang memiliki distribusi, disebut distribusi prior. Dari distribusi prior selanjutnya dapat ditentukan distribusi posterior sehingga diperoleh estimasi Bayesian [3]. Berikut langkah-langkah yang dilakukan dalam analisis metode Bayesian, yaitu:

\section{Pembentukan Fungsi Likelihood}

Pada metode Bayesian, fungsi likelihood digunakan untuk mengestimasi parameter dengan menggabungkan fungsi likelihood yang didapat dengan distribusi prior untuk menghasilkan suatu distribusi posterior. Fungsi likelihood dari distribusi eksponensial sebagai berikut:

$$
L\left(t_{i}, \theta\right)=\prod_{i=1}^{n} \theta e^{-\theta t_{i}}=\theta e^{-\theta t_{1}} \cdot \theta e^{-\theta t_{2}} \cdots \theta e^{-\theta t_{n}}=\theta^{n} e^{-\left(\theta \sum_{i=1}^{n} t_{i}\right)}
$$

\section{Penentuan Distribusi Prior}

Pada metode Bayesian, ketika suatu populasi mengikuti distribusi tertentu dengan suatu parameter di dalamnya yang dalam hal ini dimisalkan dengan $\theta$, maka kemungkinan bahwa parameter $\theta$ mengikuti suatu distribusi peluang tertentu yang disebut sebagai distribusi prior. Distribusi gamma digunakan sebagai distribusi prior untuk distribusi eksponensial dengan parameter $\theta$ dimana $0<\theta$ $<\infty$. Dimisalkan $\theta$ variabel random kontinu distribusi Gamma dengan parameter $\alpha$ dan $\beta$, fungsi kepadatan peluangnya sebagai berikut:

$$
f(\theta)=\frac{\beta^{\alpha}}{\Gamma(\alpha)} \theta^{\alpha-1} e^{-\beta \theta}
$$

\section{Penentuan Distribusi Posterior}

Distribusi posterior diperoleh dengan menggabungkan priornya dengan informasi sampel yang diperoleh dari fungsi likelihood, dimana prior ini independen terhadap fungsi likelihood [3]. Distribusi posterior Gamma dinyatakan sebagai berikut:

$$
f\left(\theta \mid t_{i}\right)=\frac{f(\theta) L\left(t_{i}, \theta\right)}{\int_{0}^{\infty} f(\theta) L\left(t_{i}, \theta\right) d \theta}
$$

dengan $f\left(\theta \mid t_{i}\right)$ merupakan distribusi posterior, $f(\theta)$ merupakan distribusi prior, dan $L\left(t_{i}, \theta\right)$ merupakan fungsi likelihood. Berdasarkan persamaan (5), (6) dan (7), maka fungsi kepadatan peluang distribusi posterior Gamma sebagai berikut:

$$
\begin{aligned}
f\left(\theta \mid t_{i}\right) & =\frac{\frac{\beta^{\alpha}}{\Gamma(\alpha)} \theta^{\alpha+n-1} e^{-\theta\left(\beta+\sum_{i=1}^{n} t_{i}\right)}}{\int_{0}^{\infty} \frac{\beta^{\alpha}}{\Gamma(\alpha)} \theta^{\alpha+n-1} e^{-\theta\left(\beta+\sum_{i=1}^{n} t_{i}\right)} d \theta} \\
= & \frac{\theta^{\alpha+n-1} e^{-\theta\left(\beta+\sum_{i=1}^{n} t_{i}\right)}}{\int_{0}^{\infty} \theta^{\alpha+n-1} e^{-\theta\left(\beta+\sum_{i=1}^{n} t_{i}\right)} d \theta}
\end{aligned}
$$




$$
f\left(\theta \mid t_{i}\right)=\frac{\left(\beta+\sum_{i=1}^{n} t_{i}\right)^{\alpha+n} \theta^{\alpha+n-1} e^{-\theta\left(\beta+\sum_{i=1}^{n} t_{i}\right)}}{\Gamma(\alpha+n)}
$$

\section{ESTIMASI PARAMETER METODE BAYESIAN LINEX}

Linear Exponential Loss Function (Linex) adalah salah satu dari loss function di dalam estimasi Bayesian. Ekspektasi posterior dari Linex loss function [6]. Berikut ini adalah ekspektasi posterior:

$$
E_{\theta}[L(\hat{\theta}-\theta)] \propto \exp (c \hat{\theta}) E_{\theta}[\exp (-c \theta)]-c\left(\hat{\theta}-E_{\theta}(\theta)\right)-1
$$

dengan $E_{\theta}$ merupakan ekspektasi posterior dengan densitas posterior dari $\theta$ dan $\hat{\theta}_{B L}$ digunakan sebagai estimator dalam Linex loss function didefinisikan sebagai berikut:

$$
\begin{aligned}
\hat{\theta}_{B L} & =-\frac{1}{c} \ln \left[E\left(e^{-c \theta}\right)\right] \\
& =-\frac{1}{c} \ln \left[\left(\frac{\beta+\sum_{i=1}^{n} t_{i}}{\beta+\sum_{i=1}^{n} t_{i}+c}\right)^{\alpha+n}\right]
\end{aligned}
$$

Sehingga estimasi fungsi survival dengan metode Bayesian Linex dari distribusi eksponensial adalah sebagai berikut:

$$
\begin{aligned}
S_{B L} & =\exp \left(-\hat{\theta} t_{i}\right) \\
& =\exp \left[\frac{1}{c} \ln \left(\frac{\beta+\sum_{i=1}^{n} t_{i}}{\beta+\sum_{i=1}^{n} t_{i}+c}\right)^{\alpha+n} t_{i}\right]
\end{aligned}
$$

\section{MODEL FUNGSI SURVIVAL DENGAN ESTIMASI PARAMETER METODE BAYESIAN LINEX}

Model fungsi yang akan digunakan untuk menghitung peluang hidup yaitu dengan pendekatan parameter metode Bayesian linex yang diperoleh berdasarkan estimasi parameter yang terbentuk. Berikut ini adalah fungsi survival peluang hidup seseorang yang berusia $t_{i}$ tahun akan hidup dalam jangka waktu (t+k) tahun:

$$
\hat{S}\left(t_{i}+k\right)_{B L}=e^{\left[\frac{1}{c} \ln \left(\frac{\beta+\sum_{i=1}^{n} t_{i}}{\beta+\sum_{i=1}^{n} t_{i}+c}\right)^{\alpha+n}\left(t_{i}+k\right)\right]}
$$

Didapatlah fungsi peluang hidup yang digunakan sebagai berikut:

$$
{ }_{k} p_{t}=\frac{s(t+k)}{s(t)}
$$




$$
=\frac{e^{\left[\frac{1}{c} \ln \left(\frac{\beta+\sum_{i=1}^{n} t_{i}}{\beta+\sum_{i=1}^{n} t_{i}+c}\right)^{\alpha+n}\left(t_{i}+k\right)\right]}}{\left.e^{\left[\frac{1}{c} \ln \left(\frac{\beta+\sum_{i=1}^{n} t_{i}}{\beta+\sum_{i=1}^{n} t_{i}+c}\right)^{\alpha+n}\right]} t_{i}^{t_{i}}\right]}
$$

Untuk fungsi peluang meninggal atau kematian adalah sebagai berikut:

$$
q_{t+k}=1-p_{t+k}=1-\frac{s(t+k+1)}{s(t+k)}=1-\frac{\left.e^{\left[\frac{1}{c} \ln \left(\frac{\beta+\sum_{i=1}^{n} t_{i}}{\beta+\sum_{i=1}^{n} t_{i}+c}\right)^{\alpha+n}\left(t_{i}+k+1\right)\right.}\right]}{\left.e^{\left[\frac{1}{c} \ln \left(\frac{\beta+\sum_{i=1}^{n} t_{i}}{\beta+\sum_{i=1}^{n} t_{i}+c}\right)^{\alpha+n}\left(t_{i}+k\right)\right.}\right]}
$$

\section{PENENTUAN PREMI ASURANSI DWIGUNA BERJANGKA $\boldsymbol{k}$ - TAHUN}

Penentuan asuransi dwiguna berjangka $k$-tahun diperoleh dengan menghitung nilai Actuarial Present Value (APV). Perhitungan Actuarial Present Value (APV) memerlukan konsep bunga untuk menentukan faktor diskon $(v)$. Faktor diskon merupakan nilai sekarang dari pembayaran. Berdasarkan estimasi parameter pendekatan Bayesian Linex maka diperoleh nilai Actuarial Present Value (APV) untuk asuransi dwiguna berjangka dan asuransi dwiguna murni sebagai berikut: Actuarial Present Value (APV) asuransi dwiguna berjangka:

$$
\begin{aligned}
& A_{t: k B}=\sum_{k=0}^{n-1} v^{k+1}\left({ }_{k} p_{t}\right)_{B L}\left(q_{t+k}\right)_{B L} \\
& =\sum_{k=0}^{n-1} v^{k+1} \frac{\left.e^{\frac{1}{c} \ln \left(\frac{\beta+\sum_{i=1}^{n} t_{i}}{\beta+\sum_{i=1}^{n} t_{i}+c}\right)^{\alpha+n}}\left(t_{i}+k\right)\right]}{\left[\frac{1}{c} \ln \left(\frac{\beta+\sum_{i=1}^{n} t_{i}}{\beta+\sum_{i=1}^{n} t_{i}+c}\right)^{\alpha+n}\right]}\left[1-\frac{\left.e^{t_{i}}\right]}{\left.e^{\left[\frac{1}{c} \ln \left(\frac{\beta+\sum_{i=1}^{n} t_{i}+1}{\beta+\sum_{i=1}^{n} t_{i}+c+1}\right)^{\alpha+n}\left(t_{i}+k+1\right)\right.}\right]}\right]
\end{aligned}
$$

Actuarial Present Value (APV) asuransi dwiguna murni:

$$
A_{t: \bar{k} B L}=v^{k} \frac{s(t+k)}{s(t)}
$$




$$
=v^{k} \frac{\left[\frac{1}{c} \ln \left(\frac{\beta+\sum_{i=1}^{n} t_{i}}{\beta+\sum_{i=1}^{n} t_{i}+c}\right)^{\alpha+n}\left(t_{i}+k\right)\right]}{\left[\frac{1}{c} \ln \left(\frac{\beta+\sum_{i=1}^{n} t_{i}}{\beta+\sum_{i=1}^{n} t_{i}+c}\right)^{\alpha+n}\right]} e^{\left.t_{i}\right]}
$$

\section{PENERAPAN MODEL SURVIVAL EKSPONENSIAL BAYESIAN LINEX PADA MODEL PREMI TUNGGAL BERSIH DWIGUNA $k$-TAHUN}

Premi tunggal bersih $k$-tahun yang merupakan penggabungan APV asuransi berjangka $k$-tahun dengan asuransi dwiguna murni. Premi dwiguna $k$-tahun dapat dinyatakan sebagai berikut [7]:

Dimana:

$$
\bar{P}\left(A_{t: \bar{k}}\right)_{B L}=b_{t}\left(A_{t: k \bar{k}} B L_{t: \bar{k} \mid}+A_{1 L}\right)
$$

$$
\begin{array}{ll}
\bar{P}\left(A_{t: k}\right)_{B L} & =\text { Premi dwiguna } k \text { tahun menggunakan model survival eksponensial Bayesian Linex } \\
b_{t} & =\text { Benefit yang diterima } \\
A_{t: k \bar{k}} B L & =\text { Actuarial Present Value asuransi dwiguna berjangka } k \text {-tahun menggunakan model } \\
& \text { survival eksponensial Bayesian Linex } \\
A_{t: \frac{1}{k} B L} & =\text { Actuarial Present Value asuransi dwiguna murni menggunakan model survival } \\
& \text { eksponensial Bayesian Linex }
\end{array}
$$

Berdasarkan persamaan (14) dan (15) maka perumusan model premi tunggal dwiguna $k$-tahun menggunakan model survival eksponensial dengan pendekatan Bayesian Linex diperoleh:

$$
\begin{aligned}
& \bar{P}\left(A_{t: k \bar{k}}\right)_{B L}=b_{t}\left(A_{t: k{ }^{\prime} B L}+A_{t: \frac{1}{k} \mid B L}\right) \\
& =b_{t}\left(\left(\sum_{k=0}^{n-1} v^{k+1}\left({ }_{k} p_{t}\right)_{B L}\left(q_{t+k}\right)_{B L}\right)+v^{k}\left({ }_{k} p_{t}\right)_{B L}\right)
\end{aligned}
$$

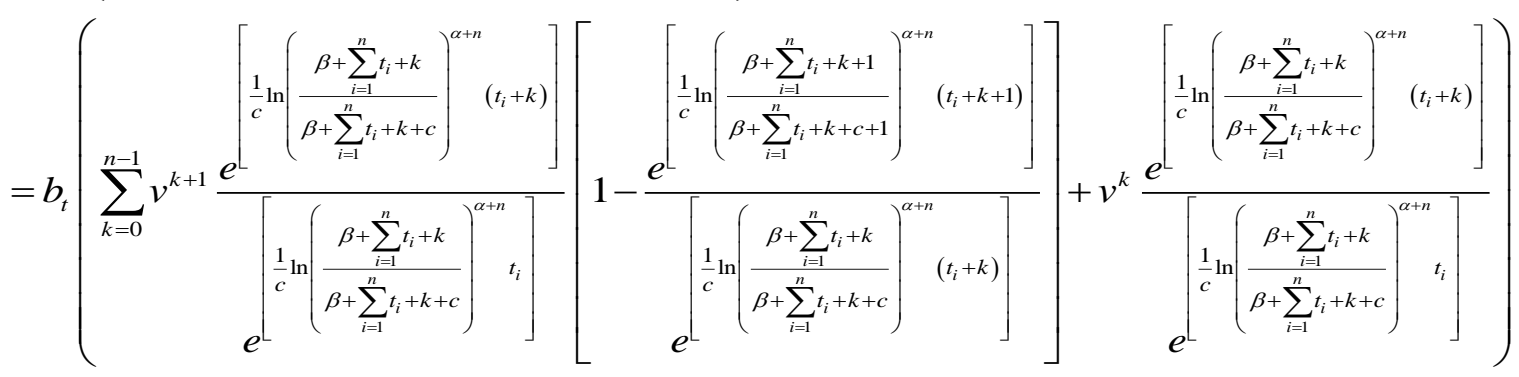

\section{STUDI KASUS}

Studi kasus yang digunakan adalah data usia seseorang dari 1 sampai 50 tahun. Dari data tersebut dilakukan uji distribusi data untuk mengetahui data berdistribusi eksponensial atau tidak. Selanjutnya estimasi parameter metode bayesian Linex pada data usia 1 sampai 50 tahun. Kemudian dilanjutkan dengan menentukan nilai premi dwiguna berjangka $k$-tahun dengan metode Bayesian Linex. Pemaparan selengkapnya adalah sebagai berikut: 


\section{Uji Distribusi Data}

Uji kecoockan (Goodness of Fit) digunakan untuk mengetahui ada atau tidaknya kesesuaian (kecocokan) model sebaran yang diasumsikan. Uji yang digunakan dalam penelitian ini yaitu uji Kolmogorov-Smirnov. Taraf nyata (Sig) yang digunakan adalah $\alpha=5 \%=0,05$. Dalam menentukan keputusan akhir untuk menolak atau menerima $\mathrm{H}_{0}$ didasarkan pada wilayah kritis $\alpha$ dengan nilai $p$ value yang mendukung suatu uji dalam bentuk peluang, jika nilai $p$-value $\leq \alpha$ maka $\mathrm{H}_{0}$ ditolak dan $\mathrm{H}_{1}$ diterima.

Tabel 1 Uji Kolmogorov-Smirnov dengan program SPSS

\begin{tabular}{cc}
\hline Uji Kolmogorov-Smirnov & Nilai \\
\hline $\mathrm{N}$ & 50 \\
\hline Exponential Parameter (Mean) & 25,5 \\
\hline Asymp Sig & 0,125 \\
\hline
\end{tabular}

Tabel 1 merupakan nilai p-value pada uji Kolmogorov-Smirnov yaitu 0,125. Nilai p-value 0,125 yang berarti ( $p$-value $>0,05$ ) sehingga cukup bukti untuk menerima $\mathrm{H}_{0}$. Jadi data berdistribusi eksponensial.

\section{Penentuan Premi Dwiguna Berjangka $k$ - Tahun}

Premi dwiguna berjangka $k$-tahun menggunakan model survival eksponensial dengan pendekatan Bayesian Linex. Premi yang digunakan pada asuransi ini adalah premi tunggal bersih, yaitu perhitungan premi yang tidak memperhatikan anuitas. Berikut ini adalah nilai premi dwiguna berjangka $k$-tahun, dengan jangka pembayaran 10 tahun, 15 tahun, dan 20 tahun:

Tabel 2 Premi Tunggal Asuransi Dwiguna Berjangka $k$ Tahun dengan Pendekatan Bayesian Linex

\begin{tabular}{lcccc}
\hline & $\begin{array}{c}\text { Asuransi Dwiguna } \\
\text { Berjangka }\end{array}$ & $\begin{array}{c}\text { Asuransi } \\
\text { Dwiguna Murni }\end{array}$ & Benefit (Juta) & Premi (Juta) \\
\hline Jangka 10 Tahun & 0.206962931 & 0.377250524 & Rp100 & Rp58.421.345 \\
\hline Jangka 15 Tahun & 0.327006441 & 0.23171 & Rp100 & Rp55.871.644 \\
\hline Jangka 20 Tahun & 0.335006312 & 0.142317958 & Rp100 & Rp47.732.427 \\
\hline
\end{tabular}

Berdasarkan Tabel 2 diperoleh masing-masing nilai Actuarial Present Value (APV) asuransi dwiguna berjangka dan asuransi dwiguna murni. Harga premi tunggal asuransi dwiguna $k$-tahun merupakan penjumlahan dari Actuarial Present Value (APV) dari asuransi dwiguna berjangka dan asuransi dwiguna murni. Kemudian nilai Actuarial Present Value (APV) tersebut dikali dengan benefit yang akan diterima. Diperoleh harga premi tunggal asuransi dwiguna berjangka $k$-tahun dengan pendekatan Bayesian Linex berdasarkan usia dari 1 sampai 50 tahun dengan jangka 10 tahun, 15 tahun, 20 tahun dan bunga 6\% per November 2018 dengan benefit atau manfaat sebesar Rp100.000.000. Setiap jangka memiliki nilai pembayaran premi yang berbeda-beda. Semakin lama jangka pembayaran premi maka harga premi yang dibayarkan oleh nasabah akan semakin murah. 


\section{PENUTUP}

Berdasarkan hasil estimasi model survival eksponensial menggunakan pendekatan Bayesian linex diperoleh model Actuarial Present Value (APV) asuransi dwiguna berjangka $k$-tahun dengan harga premi tunggal bersih dwiguna pada seseorang yang berusia 1 sampai 50 tahun dengan manfaat yang akan diperoleh sebesar Rp100.000.000 dengan jangka 10 tahun sebesar Rp58.421.345,- dengan jangka 15 tahun sebesar Rp55.871.644,- dengan jangka 20 tahun sebesar Rp47.732.427,-. Berdasarkan nilai tersebut, semakin lama jangka waktu pembayaran maka harga nilai premi yang dibayarkan oleh nasabah akan semakin murah. Hal ini akan memudahkan nasabah dalam transaksi pembayaran.

\section{DAFTAR PUSTAKA}

[1]. Undang-Undang RI Nomor 2 Tahun 1992 tentang Usaha Perasuransian. Republik Indonesia; 1992.

[2]. Setyaningsih, Hermawati. Aplikasi Suku Bunga Model Cox Ingersoll-Ross (CIR) Dalam Perhitungan Premi Asuransi Jiwa Dwiguna. Universitas Gajah Mada; 2013.

[3]. Bolstad,W.M. Introduction to Bayesian Statical Analysis. London: Addison Wesley Publishing Company; 2007.

[4]. Berger, James O. Statistical Decision Theory and Bayesian Analysis. New York: SpringerVerlag; 1985.

[5]. Lawless, J.F. Statistical Models and Method for Lifetime Data. New York: John Wiley and Sons Inc, Ed ke-2; 1982.

[6]. A. A. Soliman, A. H. Abd Ellah, and S. B. Ryan, "Comparison Of Estimates Using Record Statistics from Weibull Model: Bayesian and Non-Bayesian Approaches," Computational Statistics and data Anatysist, vol. 51, pp. 2065-2077, 2006.

[7]. Bowers NL, Gerber HU, Hickman JA, Jones DA, Nesbitt CJ. Actuarial Mathematics. Illinois: The Society of Actuaries; 1986.

FITRIANI HARTATI

SETYO WIRA RIZKI
: Jurusan Matematika FMIPA UNTAN, Pontianak fitrianihartati02@gmail.com

: Jurusan Matematika FMIPA UNTAN, Pontianak setyo.wirarizki@math.untan.ac.id

NAOMI NESSYANA DEBATARAJA : Jurusan Matematika FMIPA UNTAN, Pontianak naominessyana@math.untan.ac.id 